\title{
Enabling Broadband Internet Access Offshore using Tethered Balloons: The BLUECOM+ experience
}

\author{
Filipe B. Teixeira, Tiago Oliveira, Mário Lopes, Carlos Leocádio, \\ Pedro Salazar, José Ruela, Rui Campos, Manuel Ricardo \\ INESC TEC and Faculdade de Engenharia, Universidade do Porto \\ Rua Dr. Roberto Frias, s/n - 4200-465 Porto, Portugal \\ Email: \{fbt, ttpo, mjlopes, cmsl, psjulio, jruela, rcampos, mricardo\}@inesctec.pt
}

\begin{abstract}
The growth of the Blue Economy has been boosted by a set of traditional and new activities including maritime transportation, fisheries, environmental monitoring, deep sea mining, and inspection missions. These activities are urging for a cost-effective broadband communications solution capable of supporting both above and underwater missions at remote ocean areas, since many of them rely on an ever-increasing number of Autonomous Surface Vehicles (ASV), Autonomous Underwater Vehicles (AUV) and Remote Operated Vehicles (ROV), which need to transmit large amounts of data to shore. The BLUE$\mathrm{COM}+$ project has considered the usage of helium balloons to increase the antenna height, and overtake the earth curvature and achieve Fresnel zone clearance, combined with the use of sub-GHz frequency bands to enable long range communications.

In this paper we present the results obtained in three sea trials. They show that the BLUECOM+ architecture is capable of supporting human and system activities at remote ocean areas by enabling Internet access beyond $50 \mathrm{~km}$ from shore, live video conference calls with the quality of experience available on land, and real-time data upload to the cloud by ASVs, AUVs and ROVs using standard access technologies with bitrates above $1 \mathrm{Mbit} / \mathrm{s}$.
\end{abstract}

\section{INTRODUCTION}

The growth of the sea economy has been a reality over the past years. The sea economy involves a set of traditional and new activities, including maritime transportation, fisheries, environmental monitoring, scientific research, surveillance and inspection of oil and gas facilities. Many of these activities will rely on an ever increasing number of Autonomous Surface Vehicles (ASV), Autonomous Underwater Vehicles (AUV), and Remote Operated Vehicles (ROV), reducing the cost and duration of both surface and subsea missions. Providing wireless communications to remote ocean areas is thus essential not only to control and retrieve data collected by autonomous and remotely operated vehicles, but also to enable Internet access for end-users at sea. Furthermore, such above water communications are important to support underwater operations that may use, for example, acoustic [1], RF [2] [3], or optical [4] communications technologies. Together they will enable real-time end-to-end experience when operating with ROVs/AUVs, and support exploration of deep sea resources and monitoring activities, as being considered in the CORAL project [5].

Broadband Internet access at sea introduces additional challenges when compared with land communications due to the lack of infrastructures. Currently, HF/VHF and satellite are the only technologies available to communicate at remote ocean areas, where neither Wi-Fi nor cellular networks are available. While HF radios are able to provide long range communications, for instance in buoy-to-shore communication scenarios, they are not capable of providing broadband communications [6]. Voice communications at sea, namely ship-to-ship and ship-to-shore, rely mostly on VHF technology which is still a narrowband solution and supports voice services only [7]. When it comes to data exchange, satellite communications are the most common technology in use due to their coverage and availability; for instance, they have been successfully used for buoy-to-shore communications [8]. However, satellite communications are still narrowband [9]. In addition, providing satellite access to a large number of devices is expensive, as it requires proprietary hardware and monthly fees [10], and a consequent high cost per bit; moreover, the delay associated with satellite communications may reduce the quality of realtime communications such as voice and video conference calls. Therefore, accessing the Internet in a cost-effective way is only possible near shore in two scenarios: 1) using a $3 \mathrm{G} / 4 \mathrm{G}$ network when it is available; 2) within the range of Wi-Fi-based long distance links, typically up to $10 \mathrm{~km}$, as shown in the Mare-Fi project [9][11][12].

In the past WiMAX was seen as a candidate technology to overcome the satellite dependency for Internet access at remote ocean areas, namely for buoy-to-ship point-to-point communications and multi-hop communications using ships as relay nodes for extending the range of ship-shore communications [13] [14]. Multi-hop routing protocols and cognitive medium access control mechanisms were studied for WiMAX in this scenario as well [15]. Despite the advances achieved in the proposed solutions, communications still suffered from: 1) the water proximity of the transceiver's antenna, affecting the propagation of the signal and limiting the effective range, and 2) the undulation and the height of the waves [13] [15]. Furthermore, in the meanwhile, WiMAX became an obsolete technology.

Elevating the height of the transceiver's antenna benefits the radio frequency propagation and reduces the limitations imposed by the ocean conditions. This increase in the antenna height was already accomplished at sea, mostly for military applications [18], through the use of Helikites — a combination of a helium balloon and a kite that is easily deployable 


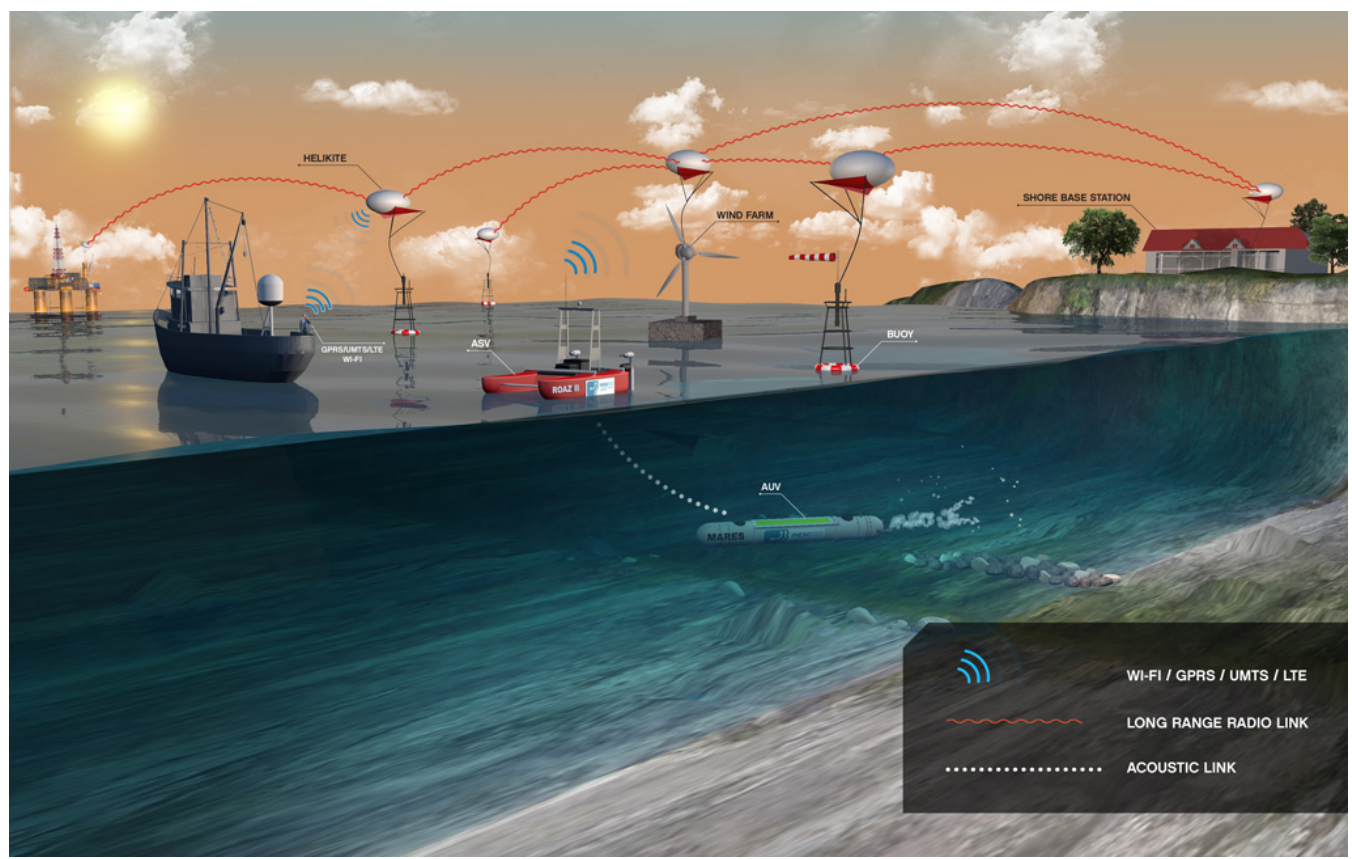

Fig. 1: BLUECOM+ concept.

and has the ability to survive to harsh environments such as high winds up to $100 \mathrm{~km} / \mathrm{h}$ [19] [20]. The unique civilian application of a Helikite known so far was demonstrated in the FP7 ABSOLUTE project, featuring a $4 \mathrm{G}$ base station for disaster scenarios through a single-hop communications architecture [16].

Through the use of a multi-hop network of tethered helium balloons, the BLUECOM+ enables cost-effective broadband communications at remote ocean areas taking advantage of the longer range of the TV white spaces frequencies [17] combined with the use of standard access technologies such as $3 \mathrm{G} / 4 \mathrm{G}$ and $\mathrm{Wi}-\mathrm{Fi}$.

In this paper we present the sea trial results, which proved that the BLUECOM+ solution is capable of providing Internet access beyond $50 \mathrm{~km}$ from shore with bitrates exceeding $1 \mathrm{Mbit} / \mathrm{s}$, enabling live video conference calls with the quality of experience available on land, and supporting real-time data collection from ASVs and AUVs. These sea trials showed that the BLUECOM+ solution is able to support human and system activities at remote ocean areas where no cost-effective broadband solution is currently available.

The rest of the paper is organized as follows. Section II describes the related work. In Section III, the BLUECOM+ concept and architecture are detailed. Section IV presents the sea trials used to validate the architecture. Section V concludes the document and points out the future work.

\section{RELATED WORK}

Over the last years there has been an effort from the academia to develop a solution for long range over sea broadband communications. Most of the solutions were based on WiMAX technology. Buoy-to-ship point-to-point commu- nications were evaluated in [13] using the license free $5.8 \mathrm{GHz}$ band near shore. In [14] the authors evaluated the WiMAX performance for ship-to-shore point-to-point communications and characterized the radio propagation at $5.8 \mathrm{GHz}$. The authors took into consideration the impact of antenna heights, the sea waves and ship's movement. A new path loss model was also proposed, together with the usage of relay buoys for extending the ship-to-shore communications range. In [15] the authors presented a multi-hop ad-hoc routing protocol and cognitive medium access control mechanism for long-range WiMAX-based ship-to-ship and ship-to-shore communications considering the sea waves and antenna heights.

The Mare-Fi project was focused on Wi-Fi based long range, broadband maritime communications for providing affordable Internet access for fisheries [11]. Within the project, a testbed, named MAREBED - MARitime wireless networks testBED, was created to evaluate the communications solution and consisted of 2 land stations and 8 fishing ships in the Atlantic coast, about 10 nautical miles from Porto. This testbed provided broadband ship-to-shore communications up to 10 $\mathrm{km}$ from shore using TV white spaces frequencies in the 700 $\mathrm{MHz}$ band [7] [9] [12]. This testbed was used to carry out a pilot for providing free Internet access to fishing ships, where the fishermen can use standard equipment, such as their smartphones, to access the Internet at sea. The range of the current solution is limited by the single-hop operation and the low height of the antennas deployed in the ships.

Helium balloons have been successfully deployed on land and sea environment for radio communications relays. Their main advantage is to increase the height of the antennas, enabling line-of-sight propagation conditions. Through the combination of a helium balloon with a kite, Helikites have 


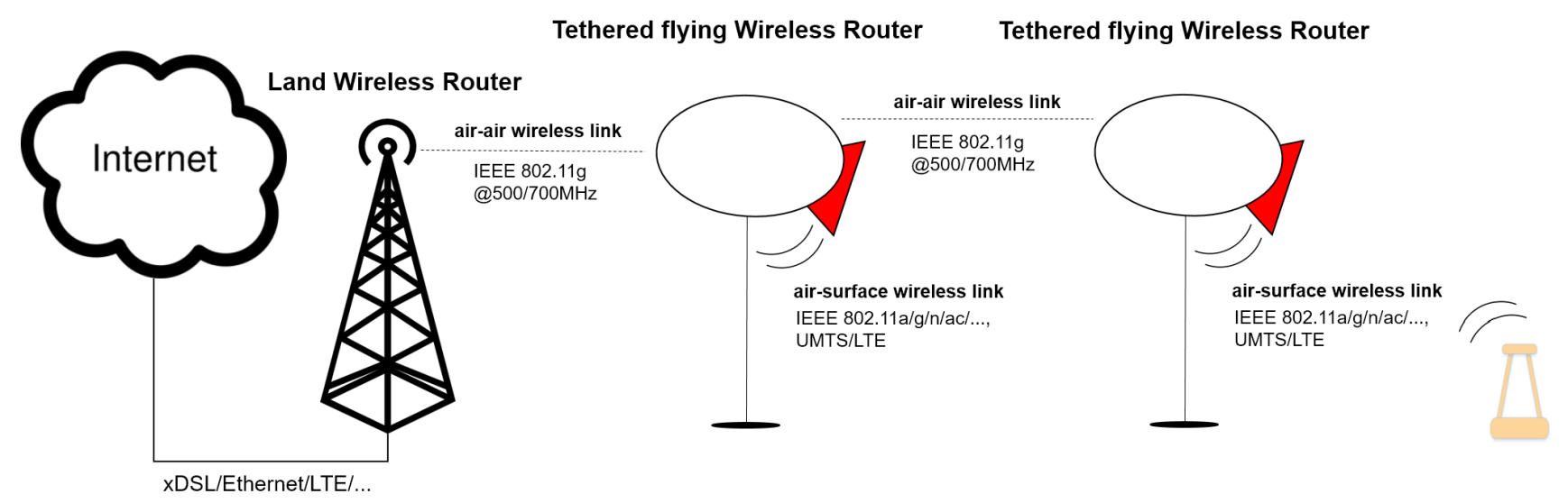

Fig. 2: BLUECOM+ communications architecture.

been proven to be easy to deploy, last up to several weeks without maintenance, and withstand wind speeds up to 100 $\mathrm{km} / \mathrm{h} \mathrm{[16]} \mathrm{[19]} \mathrm{[20].} \mathrm{They} \mathrm{have} \mathrm{been} \mathrm{mostly} \mathrm{used} \mathrm{on} \mathrm{military}$ applications [18]. In the FP7 ABSOLUTE project a 4G base station was deployed on a balloon, targeting at disaster scenarios on land. However, the communications range is limited to the single-hop architecture of the network [16].

\section{BLUECOM ARCHITECTURE}

The BLUECOM+ concept is illustrated in Figure 1. It consists in using balloons tethered to existing or new land or ocean structures, such as lighthouses, oceanographic buoys, anchored/moving ships, or any other offshore platforms, to act as base stations, repeating the signal through the flying multi-hop network shown in Figure 1. The high altitude of the balloons allows line-of-sight communications and reduces the influence of the sea conditions. This helps increasing coverage and enables an airborne backhaul network. The range of this backhaul is further increased through the usage of the sub$\mathrm{GHz}$ band made available by the release of the analogue television, also known as TV white space frequencies, where the new IEEE 802.11 af standard operates [17]. Standard access technologies, such as GPRS/UMTS/LTE and Wi-Fi at 2.4 or 5 $\mathrm{GHz}$, provide Internet access by using any legacy device. The provisioning of acoustic communications to AUVs and ROVs is also possible through a surface platform, for instance an ASV connected to the airborne network, enabling end-to-end communications between underwater devices and shore [21].

The BLUECOM+ architecture is presented in Figure 2. The balloons, named Tethered flying Wireless Routers (TWR), are lifted at altitudes up to $120 \mathrm{~m}$ to allow Fresnel zone clearance. Connections between TWRs and with the Land Wireless Router (LWR) are established over IEEE 802.11g-like low cost and low power air-air links at 500 or $700 \mathrm{MHz}$. The LWR, which is typically installed on tall buildings on shore - e.g. lighthouses - is responsible for connecting the BLUECOM+ TWR to the Internet. The air-surface wireless link to connect the clients, such as end-devices installed in buoys, is based on standard access technologies, e.g., IEEE $802.11 \mathrm{a} / \mathrm{g} / \mathrm{n} / \mathrm{ac}$ and
GPRS/UMTS/LTE. This combination allows installing a costeffective backhaul network that extends broadband Internet access to legacy devices operating in remote ocean areas.

Simulation results performed with ns-3 simulator [22] showed that air-air broadband connectivity is possible over 40 $\mathrm{km}$ using sub-GHz frequencies, while air-surface links using a IEEE $802.11 \mathrm{~g} / \mathrm{n}$ network are able to provide access over $2 \mathrm{~km}$ from the Helikite; if a LTE base station is used instead, the cell radius can exceed $30 \mathrm{~km}$. With this range and overlapping LTE cell coverage, client mobility and coverage are continuously assured from shore. Simulations also showed that the three hop link shown in Figure 2 between an end-device in a buoy and the Internet through the two TWRs enables throughputs above $1 \mathrm{Mbit} / \mathrm{s}$ with distances exceeding $50 \mathrm{~km}$ between Helikites [22].

\section{Sea Trials}

In order to validate the BLUECOM+ communications architecture and the simulation results presented in [22], a proof-of-concept prototype was built and three sea trials were performed off the Portuguese coast. The LWR was installed in Cape Espichel lighthouse at $156 \mathrm{~m}$ from the sea level (Figure 3a), while TWRs were installed in coastal and oceanographic vessels (Figure 3b). The tests were done in the Atlantic Ocean, in the area near Sesimbra. There was also a demonstration of the project in Faial island, in Azores, for exploring different LWR and TWR conditions.

\section{A. First sea trial - July 2016}

The first sea trial aimed at testing not only the performance of the single-hop air-air link and its maximum range, but also the air-surface links to end-users. One LWR and one TWR were used. The TWR was installed in Diplodus research vessel from IPMA (Figure 4a) at an altitude around $120 \mathrm{~m}$ from the sea level near Sesimbra area. During the three-day sea trial, the weather conditions varied from low wind to gusts between 20 and 30 knots, while undulation was between 1 and $2 \mathrm{~m}$. Figure $4 \mathrm{~b}$ shows the trajectory of Diplodus during the three days. 


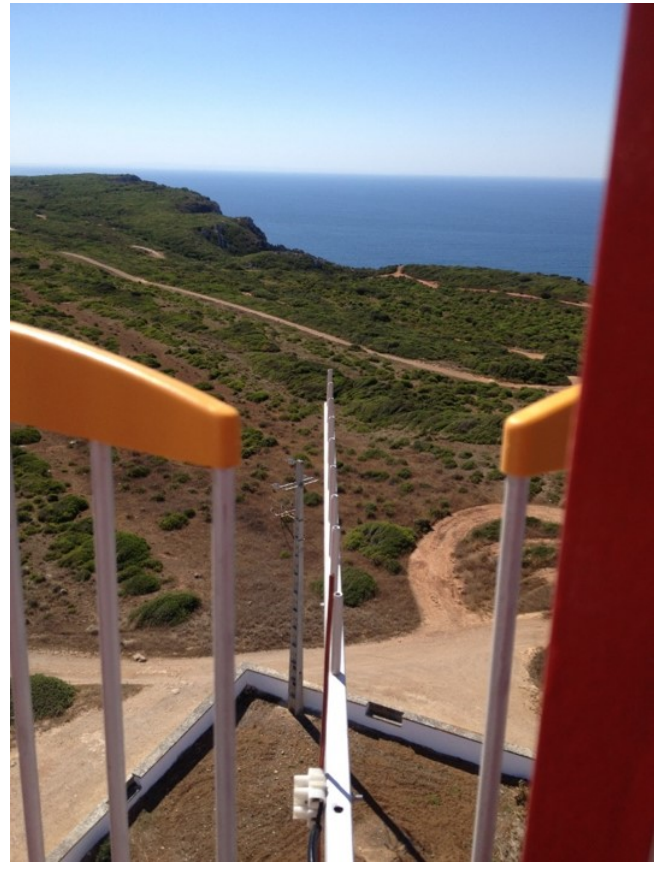

(a)

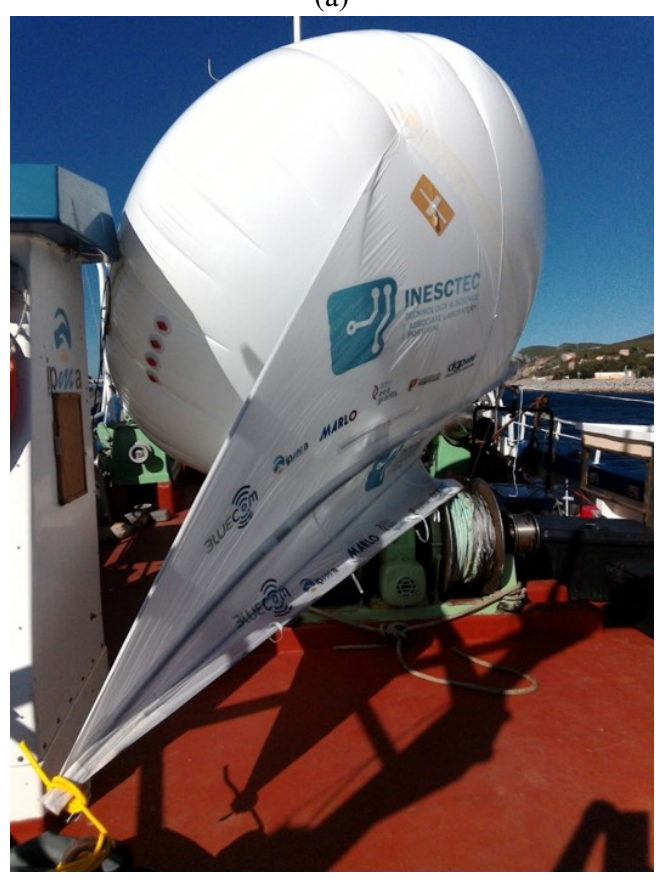

(b)

Fig. 3: a) Land Wireless Router; b) Tethered flying Wireless Router.

The experiments have proven that communications between the LWR and TWR were possible with distances up to $40 \mathrm{~km}$, with a bitrate up to $3.2 \mathrm{Mbit} / \mathrm{s}$. The connection between the TWR and the end-users was also tested with the use of INESC TEC's ROAZ ASV on the water and smartphones onboard. Video conference calls were made at $40 \mathrm{~km}$ with very good quality of experience, with no glitches in the audio or video.

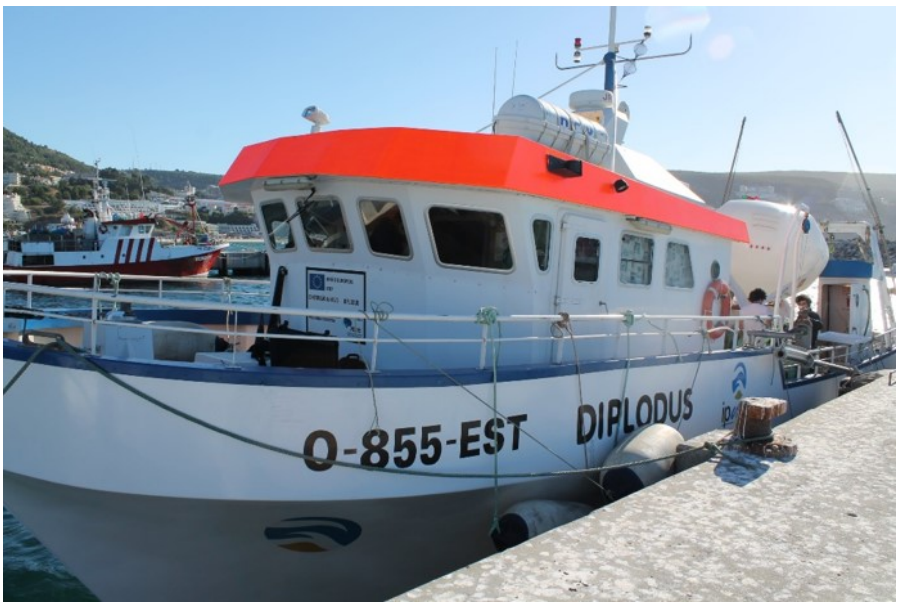

(a)

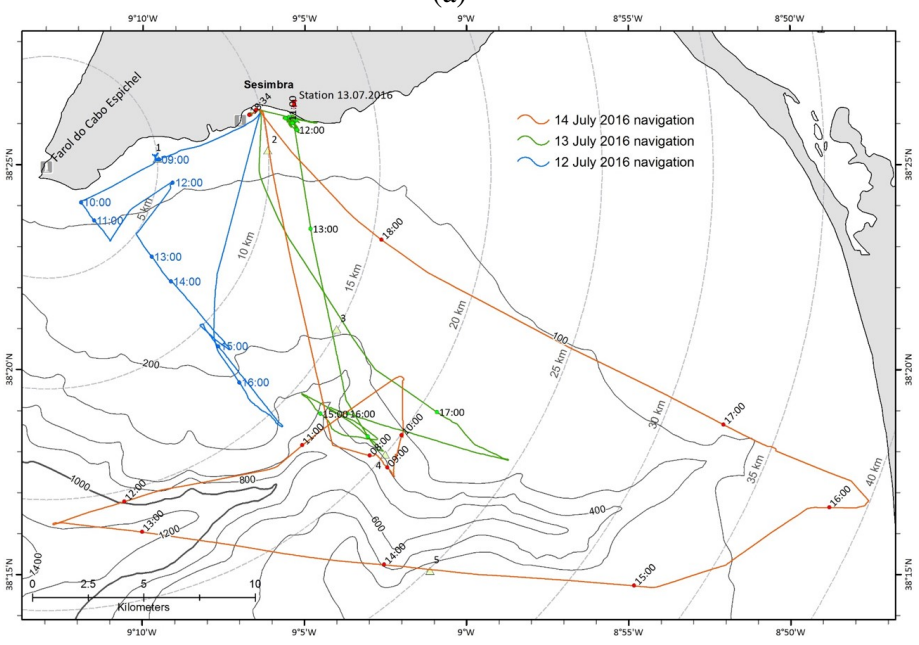

(b)

Fig. 4: a) Diplodus research vessel from IPMA; b) Trajectory of Diplodus research vessel during the first three-day sea trial.

\section{B. Second sea trial - September 2016}

The multi-hop airborne network was tested during the second sea trial. Two TWRs were installed, one in NRP Auriga ship from Hydrographic Institute (Figure 5a), acting as the first-hop, and the other one in Bolhas, a recreational vessel, used as the second-hop of the BLUECOM+ network; both balloons were deployed at around $120 \mathrm{~m}$ height.

Internet access was tested not only using equipment onboard, but also at INESC TEC's MARES AUV, where the data from a test mission was retrieved to shore (Figure $5 \mathrm{c})$. Moreover, acoustic communications were tested with a buoy connected to the BLUECOM+ network. The maximum achieved distance to shore was $45 \mathrm{~km}$ on the first hop and about $10 \mathrm{~km}$ between the two TWRs. The BLUECOM+ network was able to provide Internet access onboard at about $1 \mathrm{Mbit} / \mathrm{s}$, which was also limited by the 3G Internet access at the LWR. Video conference calls were made in different waypoints. At $42 \mathrm{~km}$ the quality of experience was still very good, again with no glitches in the audio or video. Figure 
$5 \mathrm{~b}$ shows the paths of the second three-day sea trial: green and light green on the first day, yellow and dark yellow on the second, red and light red on the third day. On average, weather conditions were better than during the first sea trial, with wind gusts lower than 20 knots and undulation at about $1-1.5 \mathrm{~m}$.

\section{Third sea trial - April 2017}

The third sea trial aimed at testing the remote control of the STR SeaSpyder Drop Camera System owned by IPMA onboard the Diplodus vessel (Figure 4a). Through the BLUE$\mathrm{COM}+$ network, the IPMA team at Lisbon office could observe and have the ability to control the SeaSpyder in real-time (Figure 6), supporting the sea team. During the sea trial, weather conditions remained stable with winds close to 10 knots and undulation about $1 \mathrm{~m}$. The third sea trial was also used to perform measurements on the received power when changing the balloon height, from sea level up to $140 \mathrm{~m}$. This will provide important measurements to increase the accuracy of the propagation model to be developed and help with the network planning in the future.

\section{Project demonstration}

A demonstration of the project was done in September 2016 in Faial island in Azores, Portugal. This demo allowed testing different sea and LWR conditions. The LWR was installed in Farol dos Capelinhos at $68 \mathrm{~m}$ from the sea level. Due to bad weather conditions, the test was confined to a single day in Arquipélago research vessel (Figure 7a) at Condor seamount area, located at about $20-30 \mathrm{~km}$ from shore. Internet access was provided to smartphones onboard with speeds over 1 Mbit/s, as shown in Figure $7 \mathrm{~b}$.

\section{CONCLUSION}

The Blue Economy is urging for a cost-effective broadband communications solution capable of supporting both above and underwater activities at remote ocean areas, especially when operating with ASVs, ROVs, and AUVs that collect large amounts of data, which need to be transmitted to shore.

In this paper we have shown how BLUECOM+ is able to provide a long-range cost-effective solution for Internet access at remote ocean areas. Through the usage of helium balloons, which allow increasing the antenna height to overtake the earth curvature and guarantee Fresnel zone clearance, together with the use of TV White Spaces to interconnect the balloons and a standard Wi-Fi network to serve clients, we have created an airborne backhaul maritime network with proven ranges exceeding $50 \mathrm{~km}$ and bidirectional communications up to 1.2 Mbit/s. Helium balloons have shown to be a durable choice and easy to manoeuvre at low wind speeds. However, their relatively large size may be an issue for small vessels. In such cases, a tethered drone might be a good alternative for raising the height of the antenna.

As future work, we plan to estimate the best propagation model that matches the received power levels measured during the sea trials and develop an algorithm for maximizing the

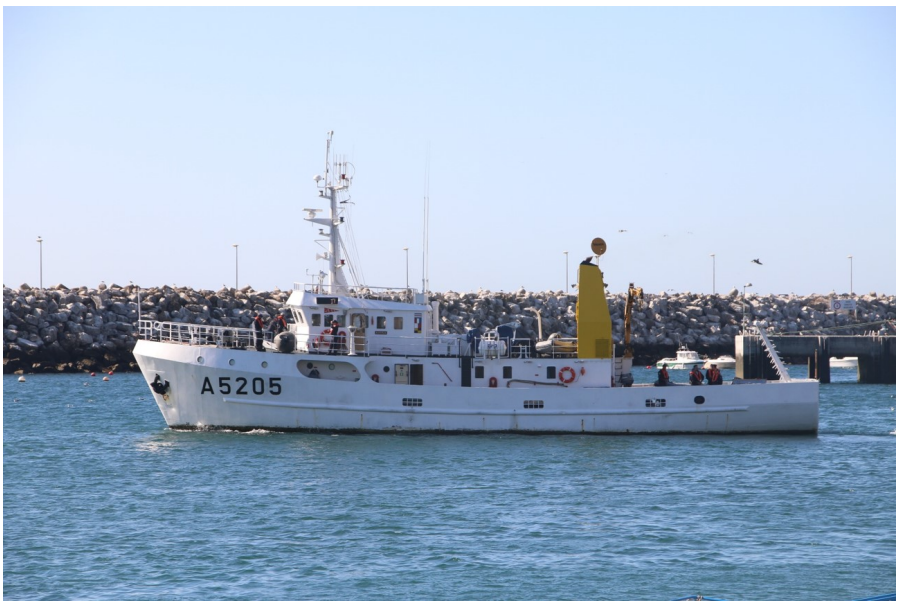

(a)

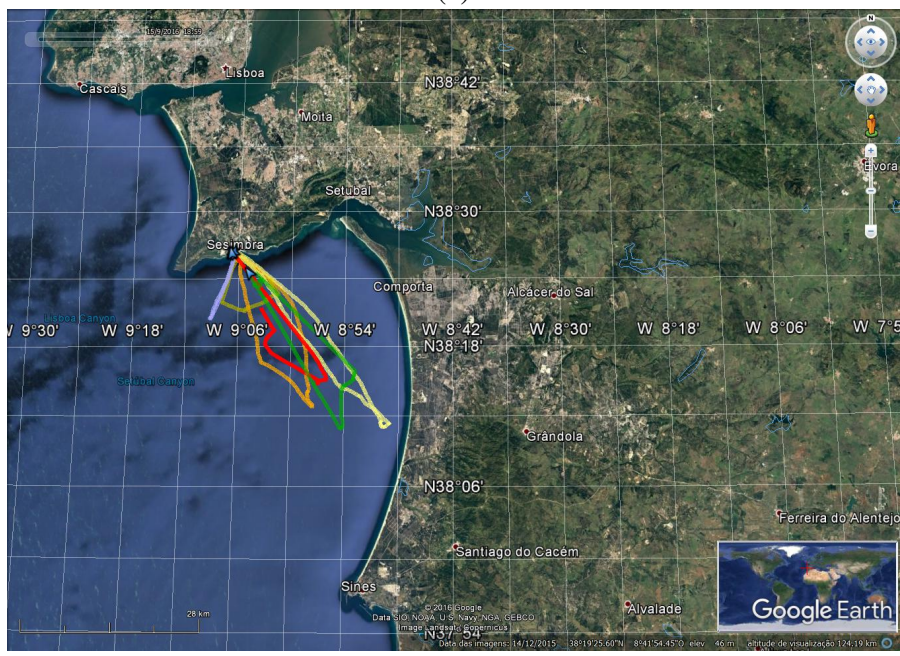

(b)

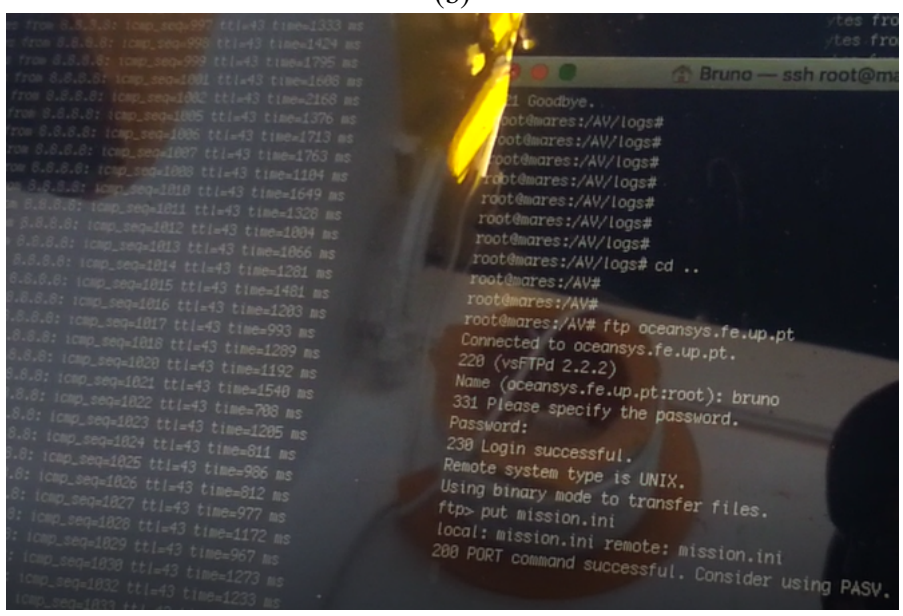

(c)

Fig. 5: a) NRP Auriga vessel from Hydrographic Institute; b) Trajectory of Auriga and Bolhas vessels during the three-day second sea trial; c) data retrieval from MARES AUV to shore.

range by optimizing the height of the balloons, taking advantage of the signal reflections in the sea surface. In addition, 


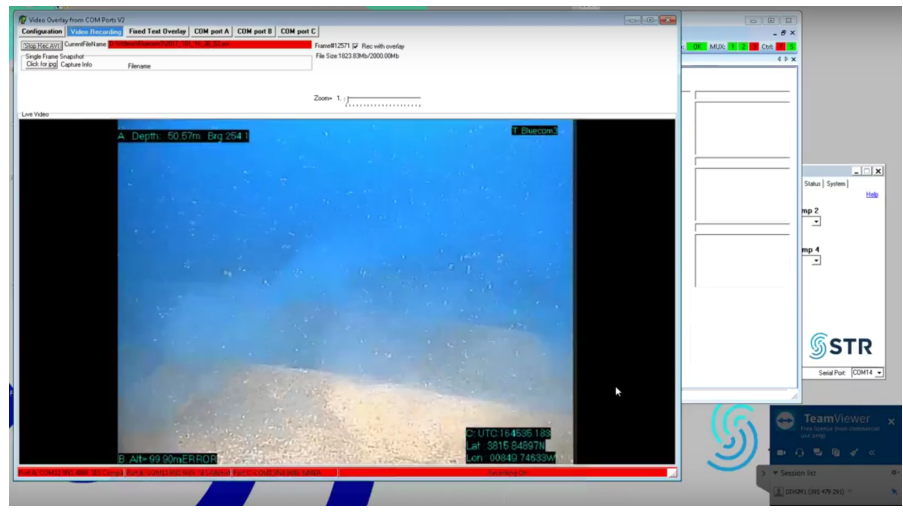

Fig. 6: STR SeaSpyder remote control using TeamViewer through the BLUECOM+ network.

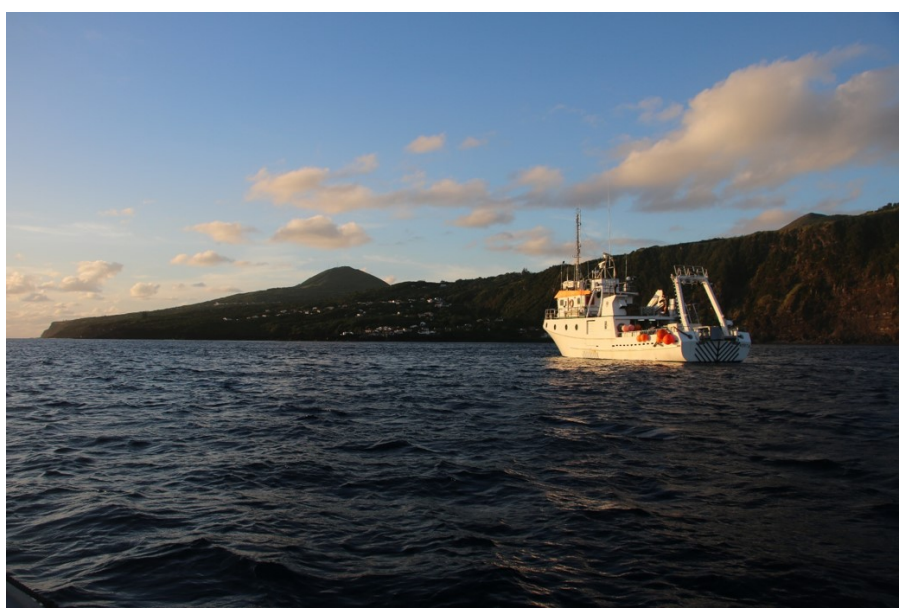

(a)

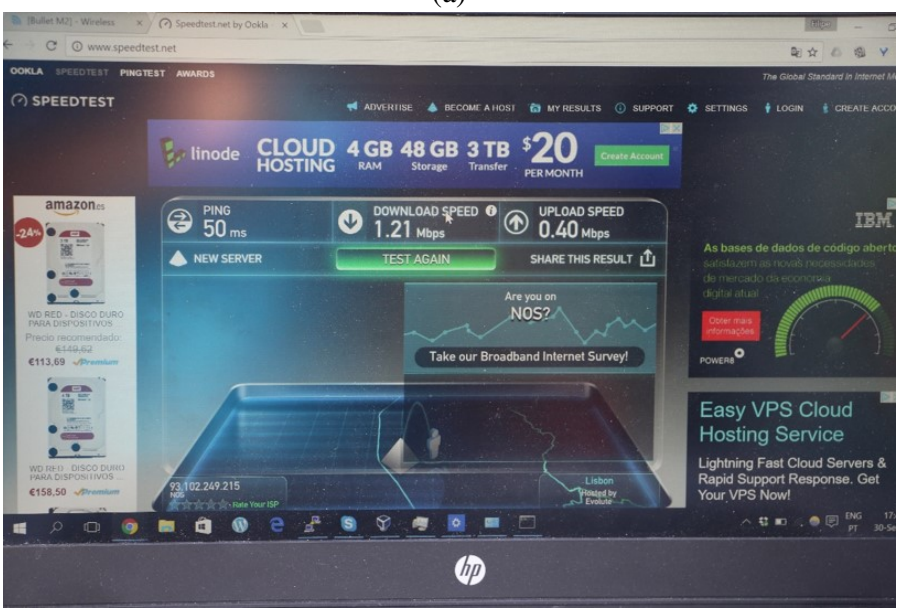

(b)

Fig. 7: a) Arquipélago research vessel; b) Internet throughput from the Condor seamount area.

we will consider possible solutions to stabilize the antenna deployed in the balloons, in order to improve the link quality, and increase the communications range.

\section{ACKNOWLEDGMENT}

This work is part of the project Coral: Sustainable Ocean Exploitation: Tools and Sensors (NORTE-01-0145-FEDER000036), financed by the North Portugal Regional Operational Programme (NORTE 2020), under the PORTUGAL 2020 Partnership Agreement, and through the European Regional Development Fund (ERDF), the project BLUECOM+: Connecting Humans and Systems at Remote Ocean Areas using Cost-effective Broadband Communications (PT02 Aviso4 0005), supported by the EEA Grants Iceland, Liechtenstein and Norway, and the project STRONGMAR: STRengthening MARritime technology Research Center (H2020-TWINN2015 (CSA)-692427).

The first author would like to thank the support from the Portuguese Foundation for Science and Technology (FCT) under the scholarship SFRH/BD/88080/2012.

\section{REFERENCES}

[1] X. Lurton. An Introduction to Underwater Acoustics - Principles and Applications. Springer, 2010.

[2] F. Teixeira, J. Santos, L. Pessoa, M. Pereira, R. Campos, M. Ricardo, Evaluation of Underwater IEEE 802.11 Networks at VHF and UHF Frequency Bands using Software Defined Radios, in Proc. of WUWNet'15, Washington DC, October 2015.

[3] F. Teixeira, P. Freitas, L. Pessoa, R. Campos, M. Ricardo, Evaluation of IEEE 802.11 Underwater Networks Operating at $700 \mathrm{MHz}, 2.4 \mathrm{GHz}$ and $5 \mathrm{GHz}$, in Proc. of WUWNet'14, Rome, Italy, November 2014.

[4] G. Cossu, R. Corsini, A. Khalid, S. Balestrino, A. Coppelli, A. Caiti, and E. Ciaramella, Experimental Demonstration of High Speed Underwater Visible Light Communications, in Proc. of IWOW'13, pp. 11-15, October 2013.

[5] INESC TEC, CORAL project, 2017. [Online]. Available: http://win.inesctec.pt/Projects. [Accessed: 21-April-2017].

[6] V. Jodalen, B. Solberg, A. Eggen, A. Leere, K. Gronnerud, IP over HF as a bearer service for NATO formal messages, in Proc. of the Ninth International Conference on HF Radio Systems and Techniques, Bath, UK, June 2003.

[7] Luciano Santos, Wi-Fi Maritime Communications using TV White Spaces, M.Sc. Thesis, University of Porto, Porto, July 2013.

[8] J. N. Walpert, N. L. Guinasso, L. L. Lee and R. D. Martin, Texas Automated Buoy System - Sustainable Ocean Observations to Help Protect the Environment, OCEANS'11 MTS/IEEE KONA, Waikoloa, HI, September 2011.

[9] M. Lopes, F. Teixeira, J. Mamede, R. Campos, Wi-Fi Broadband Maritime Communications Using $5.8 \mathrm{GHz}$ Band, in Proc. of UComms'14, Sestri Levante, Italy, September 2014.

[10] G. Leerujikul and C. Jittawiriyanukoon, Performance Evaluation for TCP with Traffic Shaping Over Satellite Communications, 2005 2nd Asia Pacific Conference on Mobile Technology, Applications and Systems, Guangzhou, November 2005.

[11] INESC TEC, Mare-Fi project, 2017. [Online]. Available http://win.inesctec.pt/Projects. [Accessed: 21-April-2017]

[12] P. Mónica et al., TEC4SEA - A Modular Platform for Research, Test and Validation of Technologies Supporting a Sustainable Blue Economy, in Proc. of OCEANS'14, St. John's, Canada, September 2014.

[13] J. Reyes-Guerrero, M. Bruno, L. Mariscal, A. Medouri, Buoy-to-ship Experimental Measurements Over Sea at $5.8 \mathrm{GHz}$ Near Urban Environments, in Proc. of the 11th Mediterranean Microwave Symposium, Cyprus, September 2011.

[14] R. Garroppo, S. Giordano, D. Iacono, Experimental and Simulation Study of a WiMAX System in the Sea Port Scenario, in Proc. of the IEEE International Conference on Communications, Dresden, Germany, June 2009.

[15] W. Ejaz, K. Manzoor, H. Kim, B. Jang, G. Jin, H. Kim, Two-state Routing Protocol for Maritime Multi-hop Wireless Networks, Journal of Computers and Electrical Engineering, vol. 39, Issue 6, pp. 1854-1866, August 2013. 
[16] A. Valcarce et al., Airborne Base Stations for Emergency and Temporary Events, in Proc. of the 5th International Conference on Personal Satellite Services (PSATS), Toulouse, France, June 2013.

[17] IEEE 802.11 Work Group. 802.11af-2013 - IEEE Standard for Information technology - Telecommunications and information exchange between systems - Local and metropolitan area networks - Specific requirements Part 11: Wireless LAN Medium Access Control (MAC) and Physical Layer (PHY) Specifications Amendment 5: Television White Spaces (TVWS) Operation.

[18] I. Bucaille, S. Héthuin, A. Munari, R. Hermenier, T. Rasheed, S. Allsopp, Rapidly Deployable Network for Tactical Applications: Aerial Base Station with Opportunistic Links for Unattended and Temporary Events, in Proc. of IEEE Military Communications Conference 2013, San Diego, CA, USA, November 2013.

[19] S. Chandrasekharan et al., Designing and Implementing Future Aerial Communication Networks, IEEE Communications Magazine, vol. 54, no. 5, pp. 26-34, May 2016.

[20] S. Allsopp, Emergency Airborne 4G Comms to Aid Disaster Traffic Management, in Proc. of Road Transport Information and Control Conference 2014 (RTIC 2014), London, UK, October 2014.

[21] R. Campos, T. Oliveira, N. Cruz, A. Matos, J.M. Almeida, BLUECOM+: Cost-effective Broadband Communications at Remote Ocean Areas, in Proc. of OCEANS'16, Shanghai, April 2016.

[22] F. B. Teixeira, T. Oliveira, M. Lopes, J. Ruela, R. Campos, M. Ricardo, Tethered Balloons and TV White Spaces: A Solution for Real-time Marine Data Transfer at Remote Ocean Areas, in Proc. of UComms'16, Lerici, Italy, September 2016. 